Int. J.Morphol.,

39(1):77-83, 2021.

\title{
Organ Histopathological Associations with Hyperostosis Frontalis Interna in Humans
}

\author{
Asociaciones Histopatológicas de Órganos con Hiperostosis Frontal Interna en Humanos
}

Brian Beatty ${ }^{1,2}$; Krishna Putcha ${ }^{1}$; Abhishek Shah ${ }^{1} \&$ Kevin Li $^{3}$

\begin{abstract}
BEATTY, B.; PUTCHA, K.; SHAH, A. \& LI, K. Organ histopathological associations with hyperostosis frontalis interna in humans. Int. J. Morphol., 39(1):77-83, 2021.

SUMMARY: An increased thickening of the frontal bone by irregular laminar additions on the inner surface just deep to the dura mater have been known in the archaeological and medical record as hyperostosis frontalis interna (HFI). The distribution of this is idiosyncratically restricted to the frontal and has no known etiology. The prevalence among post-menopausal females and rarity in males suggests that it is hormonally driven. Here we report histopathological findings of particularly hormonally active organs (pituitaries, gonads and liver) from a geriatric cadaveric sample in which HFI is assessed. HFI was present in $50 \%$ of males (7/14) and 95\% (21/22) of females. All males with HFI had testicular atrophy or had testes absent. Males with HFI category C or D had moderate to severe testicular atrophy. Decreased numbers of interstitial cells (Leydig cells) were present in $83.3 \%$ of males with HFI. All but one female (21/22) from this study exhibited evidence of HFI, and ovarian pathologies were unevenly distributed (fibromas in two) and most exhibited signs of being healthy and post-menopausal. Liver pathologies had opposite patterns between the sexes, with more liver pathologies occurring among males without HFI (particularly passive congestion and bile stasis). The only exceptions were that the one case of liver neoplasia was found in a male with HFI and steotosis was found in two cases with HFI and one case without HFI. In females all cases of liver pathologies (steotosis, hepatitis, passive congestion, fibrosis, and bile stasis) were associated with HFI. It appears that gonadal pathology is most closely associated with HFI in males but not females, suggesting that the role of estradiol in this unusual growth of bone in geriatric humans may be worth investigating further.
\end{abstract}

KEY WORDS: Hyperostosis frontalis interna; Cranium; Bone growth; Estradiol; Histology.

\section{INTRODUCTION}

Abnormal bone growth is a common type of pathology that varies greatlyin its appearance (Mann \& Hunt, 2005), largely because the development and physiology of bone and related mesodermal structures is complex (Hall, 2005). The development of dermal bones and how they relate to the dura mater is particularly important in this way, as this relationship can limit the available space for central nervous system growth (Opperman et al., 1993; Presley, 1993; Jeffery, 2002). One such abnormal growth that is extremely common, yet whose etiology is still unknown, is hyperostosis frontalis interna (HFI). HFI is characterized by lumpy growths of bone on the inner surface of the frontal bone, some of which can be almost a centimeter in additional thickness. MicroCT studies differentiate it from other skull thickening diseases such as Paget's disease quite clearly, yet also illustrate that simple lateral x-rays do not sufficiently allow their identification (Rühli et al., 2007). The best means to recognize it remains observation from the inside of the skull, either visually or by reconstructed CT. For this reason, HFI has been studied more by archaeologists and anthropologists than by physicians (Hershkovitz et al., 1999).

HFI is best known from archaeological studies in which the skulls are studied without available medical records or soft tissues (Hershkovitz et al.). Because of its prevalence in $80 \%$ of post-menopausal women, many archaeologists use it as a means to identify the sex of partial skulls (Devriendt et al., 2004; Belcastro et al., 2006; Mulhern et al., 2006). Incidence of HFI in men is rare, and the magnitude of manifestation is less severe when reported (Hershkovitz et al.). Thus, there may be some hormonal correlations with HFI, such as estrogen or testosterone levels, which affect the distinguishable presence and severity of HFI in men versus women.

\footnotetext{
${ }^{1}$ NYIT College of Osteopathic Medicine, Northern Blvd, Old Westbury, New York 11568, USA.

${ }^{2}$ United States National Museum, Smithsonian Institution, Washington, DC 20560, USA.

${ }^{3}$ Syosset High School, Syosset, NY 11791, USA.
} 
Investigations of abnormal growth at the interface between dura and bone are uncommonly done in living human patients because of the risks to vital structures, resulting in most research to be limited to animal models, cadavers, and radiological studies of living human subjects. Due to regulations on access to medical records for cadaveric studies, this presents a conundrum of sorts. To best identify the etiology of these abnormal growths, it would be best to link them to medical history. However, to study their morphology, some of the most effective methods are invasive (including histopathology) and are difficult to access in living people.

The prevalence of HFI in women and the challenge of recognizing it in living people have caused this to be relatively less studied. No negative symptoms have been identified yet for HFI, but this may be due to its prevalence causing its effects to be considered normal. But, just as hyperostoses of the dura and ligaments around the spinal cord can cause problems (Dunlop \& Stirling, 1996), it isn't unreasonable to consider that the prevalence of HFI in postmenopausal women may be linked to other prevalent symptoms in this population, such as migraines (Stewart $e t$ al., 1992). Hormonal relationships during the course of a woman's life may be an effect of HFI. Findings which show that greater magnitudes of HFI increase with age (Hershkovitz et al.) further support this theory. During the course of normal menstrual cycles in young women, follicle stimulating hormone (FSH) and luteinizing hormone (LH) are released from the pituitary to regulate the cycle, and estradiol is produced by the ovaries. When a woman becomes menopausal, the levels of FSH and LH increase, while estradiol and progesterone levels decrease. Ovarian produced estradiol directly affects the pituitary and thus plays an essential role in the hypothalamic-pituitary-gonadal axis which regulates gonadotropin production (Morishima et al., 1995; Meethal et al., 2009). One may suggest that a decrease in estradiol increases the presence of HFI. According to this assumption, post-menopausal women and men with decreased testosterone levels should present with HFI.

In women, estradiol is produced by the ovaries. In men, interstitial cells (Leydig cells) in the testes produce testosterone, which is then converted to its active metabolites, one of which is estradiol (Carani et al., 1997). In both sexes, estradiol is also produced in the arterial walls and the brain (Meethal et al., 2009). Since estradiol is thus found in excess in the cranial region, it makes sense that a change in estradiol would affect that area. Additionally, enterohepatic circulation contributes to maintaining estradiol levels since it is conjugated in the liver by sulfate and glucuronide formation. Estradiol is also known to be linked with cholestasis, which histologically presents as bile stasis (Kobayashi et al., 2013).
Thus, abnormal liver states and diseases, such as an increase in estrogenic levels leading to cirrhosis, hepatitis, or even resulting bile stasis may affect the presence of HFI.

According to Hershkovitz et al. there are 4 categories of HFI, varying in the size and location of the hyperostosis. Type A is classified as elevated bony overgrowths that may be unilateral, bilateral, single, or multiple. They are generally less than $10 \mathrm{~mm}$ in size with indented margins. Type B overgrowths are more nodular and do not have discrete margins. Type $\mathrm{C}$ is identified by more extensive nodular overgrowth than $\mathrm{B}$ and greater, more irregular thickening of the bone that can cover up to $50 \%$ of the frontal endocranial surface and can be greater than $10 \mathrm{~mm}$. Type $\mathrm{D}$ is classified as a continuous overgrowth covering more than $50 \%$ of the frontal endocranial surface. The size will be greater than $10 \mathrm{~mm}$, with sharp, clearly demarcated margins.

This makes HFI easy to recognize in cadaver populations. Human cadavers in anatomy labs are a resource for sampling histopathology that one cannot attain from anthropology osteological collections. Though HIPPAA rules prevent access to medical records that would make these cadavers more useful in the interpretation of associations of the share etiology of HFI and other pathologies, the ability to extensively sample the tissues of cadavers is an asset in comparison to the limits of biopsy in living people. Also, HFI in females is extremely common in anatomy lab populations because the average ages of body donors tend to be among the elderly, including males that mostly lack HFI and postmenopausal women that have it. Together, this makes the sampling of cadavers from anatomy lab an opportunity to thoroughly sample a sample of appropriate age. Here, we have histologically sampled the livers, gonads, and pituitaries of cadavers over a period of 3 different years, accumulating data for 36 individuals. Associating histopathological findings with the appearance of HFI in cadavers here will allow us assess the assumption that HFI is linked to changes in hormone levels.

Does HFI significantly differ in its distribution among males and females from the Anatomy Lab cadaver sample? If not, then we should expect the distribution of HFI to be equal among males and females when controlled for age. If so, the distribution of HFI should be greater among females than among males in older age groups that include postmenopausal women. Among males with HFI, is there significant evidence of a greater prevalence of endocrine disrupting pathology? If not, then the distribution of HFI among men should not significantly relate to the distribution of endocrine disrupting pathologies. If so, the distribution of HFI among men should significantly relate to the distribution of endocrine disrupting pathologies, such as 
testicular atrophy and decreased numbers of interstitial cells. Lastly, is there a relation between liver abnormalities and HFI? If not, the distribution of HFI should show no significant correlation with liver pathologies. If so, the distribution of HFI should significantly relate to liver pathologies found.

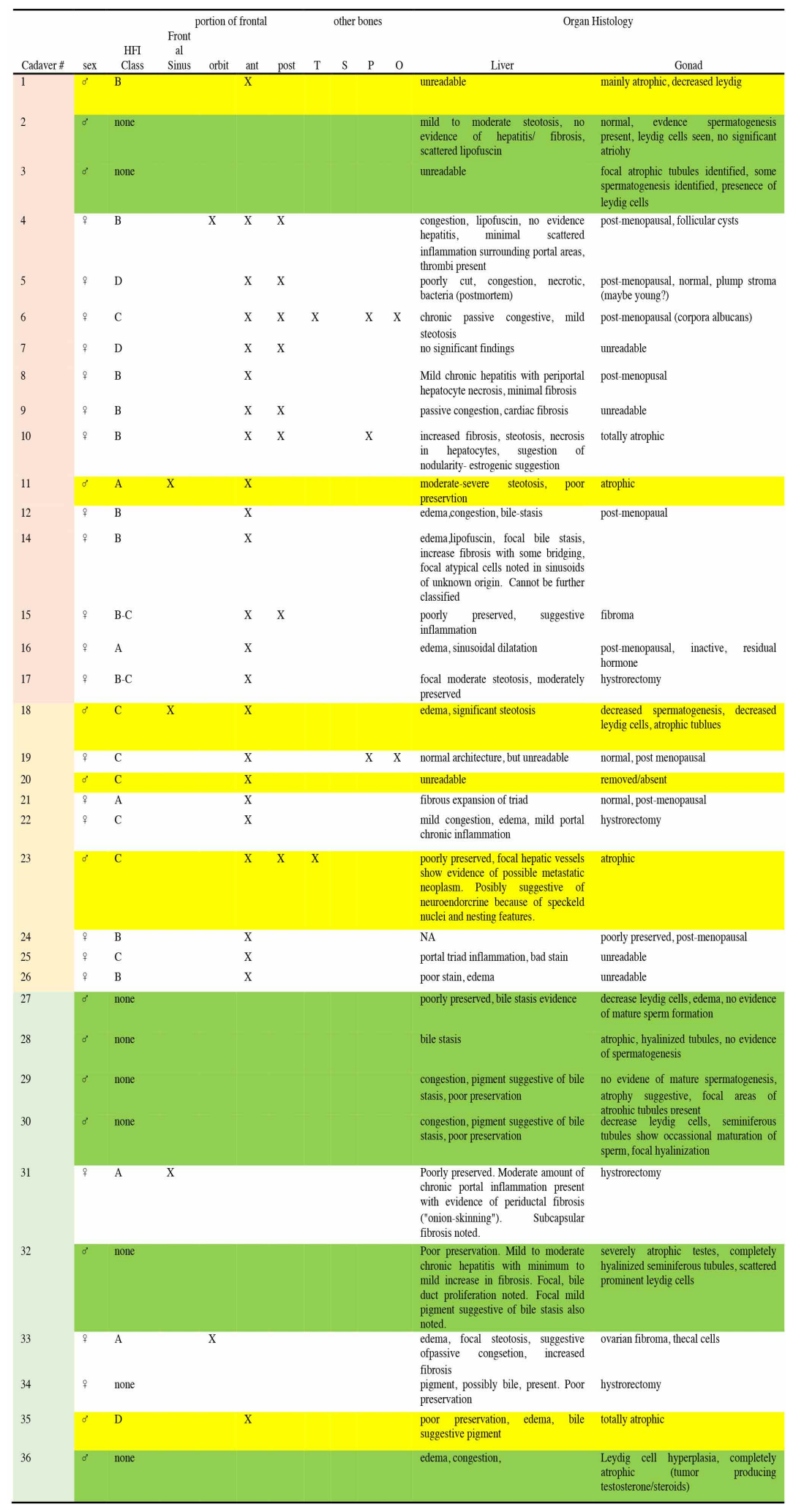

\section{MATERIAL AND METHOD}

Cadavers from the Anatomy Lab at the NYIT College of Osteopathic Medicine were used in this study. Cadavers sampled included 14 males and 22 females (Table I). Because these specimens do not meet the definition of a human subject according to the IRB, they do not require IRB exempt review. The study was HIPAA compliant and adhered to the tenets of the Declaration of Helsinki. Each individual was given a unique ID number by the NYITCOM Anatomy Lab to protect their identity from the authors.

For each individual, the deep surface of the cranial fossa was inspected for evidence of HFI, including distinct regions and the severity. The regions included were the different portions of the frontal, including the frontal sinus, orbital roof and anterior and posterior portions of the frontal's contribution to the calvarium. In addition, HFI extending beyond the frontal was noted if present on the temporal, sphenoid, parietal, and occipital. For each individual, the grade of HFI severity followed the standardized way done for archaeological specimens to ensure data equivalency (Hershkovitz et al.). Photographs of the deep surface of the calvaria were taken for reference.

In addition, tissue samples of livers, pituitaries, and gonads were collected, if available. All tissues were placed in cassettes and were processed in the NYIT College of Osteopathic Medicine Histology Lab by Alice O'Connor. Once sectioned

Table I. Data for each individual in this study, including sex, HFI status, and histopathology of liver and gonads. For HFI status, other bones include temporal (T), sphenoid (S), parietal (P), and occipital $(\mathrm{O})$. 
and stained with hematoxylin and eosin, slides were studied using a bright field light microscope and with consultation by Dr. Maria Plummer (clinical pathologist) for confirmations of interpretation.

\section{RESULTS}

Out of the 36 cases examined, some level of HFI was present in $50 \%$ of males and $95 \%$ of females. All males with HFI had testicular atrophy or had the testes surgically removed pre-mortem. Of the males that did

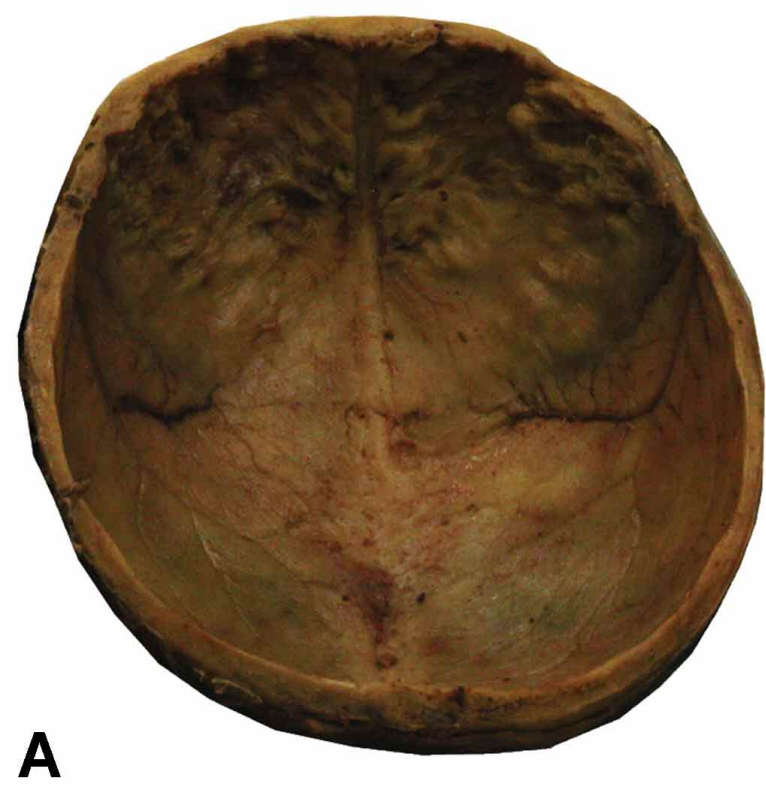

have HFI, category $\mathrm{C}$ was most commonly present, appearing in $25 \%$ of all males. All male cases with HFI category $\mathrm{C}$ had moderate testicular atrophy and $100 \%$ of male cases with HFI category D displayed a severe amount of testicular atrophy (Figs. 1 and 2). Decreased numbers of interstitial cells were present in $83.3 \%$ of males with HFI and across each category of HFI, indicating a correlational trend between decreased numbers of interstitial cells and the presence of HFI. Some form of testicular atrophy was common for most of the males in this study, though the only healthy individual and all of the males that showed only slight evidence of atrophy all lacked evidence of HFI.

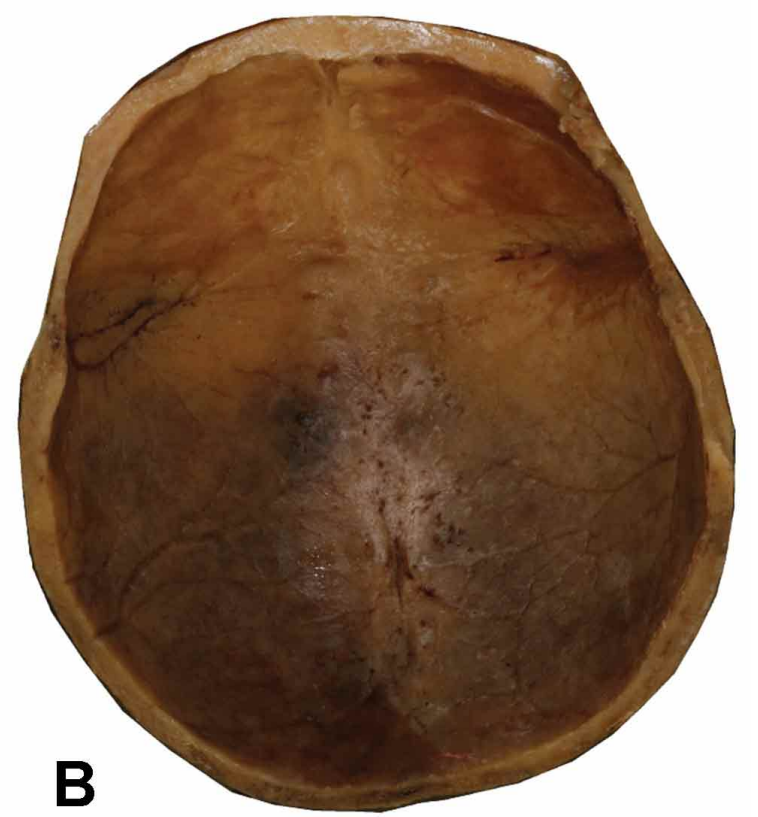

Fig. 1. Males with Class D HFI.
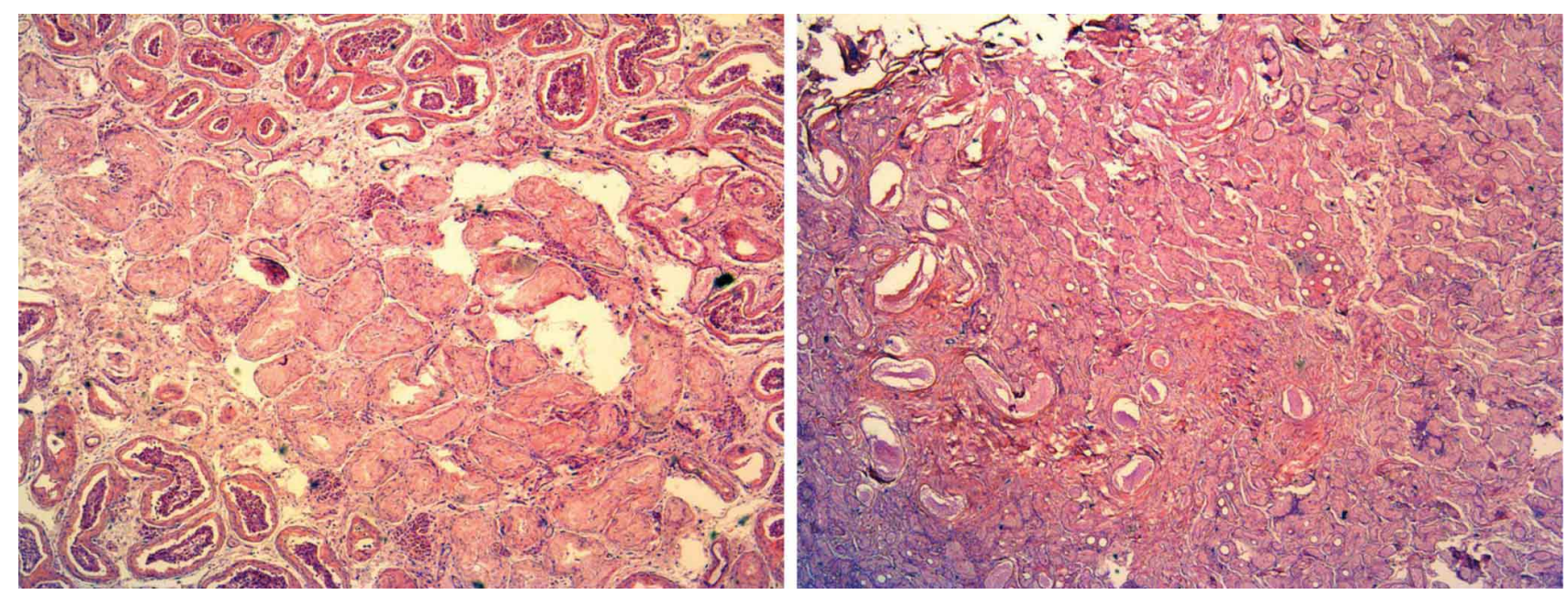

Fig. 2. Microscopic images of testicular atrophy and decreased interstitial cells (Leydig cells) presence. Pictures taken at 2x zoom (right) and $4 \mathrm{x}$ zoom (left). 
All but besides one female (21/22) from this study exhibited evidence of HFI. Ovarian tissues from these provided evidence of fibromas in two, complete atrophy in one, and being healthy and post-menopausal in nine. Four were too poorly preserved to read and four were unavailable because of pre-mortem hysterectomy.

Liver pathologies were chosen by the most frequent observations made on the histology of the samples taken (Fig. 3). Males had largely negative associations of HFI with liver pathologies. A negative pattern was found between bile stasis and HFI in males, such that 5 of the of cases without
HFI had bile stasis and only one of the males with HFI had bile stasis. Similarly, of the four cases with signs of passive congestion, one male with hepatitis, and one male with signs of fibrosis, none of them showed evidence of HFI. The only exceptions were that the one case of liver neoplasia was found in a male with HFI and steotosis was found in two cases with HFI and one case without HFI.

Female cases generally had the opposite pattern, where all cases of liver pathologies were associated with HFI. There were four cases of steatosis, one of hepatitis, six of passive congestion, six of fibrosis, and two of bile stasis.
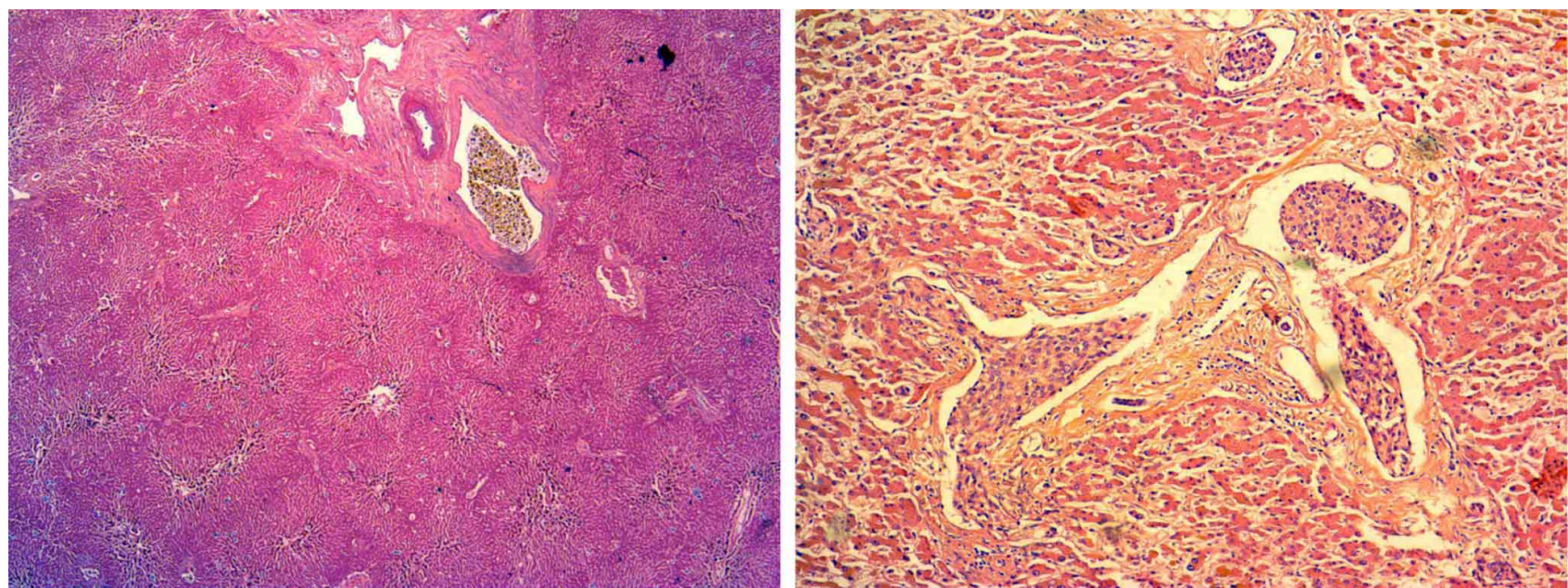

Fig. 3. Microscopic image of a liver at 2x zoom with extreme bile stasis, nodular cirrhosis, and possible cirrhotic implications (left). Microscopic image of focal hepatic vessels at 10x zoom that show evidence of a metastatic neoplasm of neuroendrocrine origin (right).

\section{DISCUSSION}

HFI is found more frequently in women than men (Hershkovitz et al.), leading us to we hypothesize that there may be some endocrine related origin or correlation, specifically in relation to estradiol. Estradiol is produced in women during their menstrual cycle and is the essential messenger hormone in the hypothalamus-pituitary-gonadal axis that regulates hormonal secretion and the menstrual cycle (Morishima et al., 1995; Meethal et al., 2009). In postmenopausal women, estradiol concentration decreases drastically, roughly to the same level found in men. Men produce estradiol as an essential metabolite of testosterone, produced in the interstitial cells. Decreased numbers of interstitial cells result in less testosterone, which thus results in a decreased concentration of estradiol (Carani et al., 1997). Estradiol is also found in the brain and in the arterial walls (Meethal et al., 2009), possibly contributing to the development of HFI.
In this study, there was a correlation found between atrophic testes and the presence of HFI. Furthermore, 83.3 $\%$ of males that had HFI also showed decreased numbers of interstitial cells in the histology samples taken. In accordance with our hypothesis, these findings suggest that most men with HFI had decreased testosterone production, and thus a decreased amount of estradiol. Since there is no current access to cadaveric medical records, it is unclear as to what age the atrophic states in these males began and if there was any physiologic manifestation recorded. Additionally, the severity of the atrophy was seen to increase as the level of HFI increased, with all males that had HFI category $\mathrm{C}$ showing moderate atrophy and all males with HFI category D showing severe atrophy. These findings suggest that the level of HFI increases as the drop of estradiol from the baseline increases. Since most of the female cadavers were of post-menopausal age, their ovarian samples appeared 
hyalinized, which is normal in post-menopausal women (O'Neill \& Eden, 2017). This is consistent with the postmenopausal drop in estradiol production and the greater frequency of HFI found in post-menopausal women.

Estrogenic effects are also found on the liver because estradiol undergoes hepatic metabolism (Kobayashi et al., 2013). The most common findings and estrogen related pathologies in this study were recorded when the histology was viewed. A significant inverse relationship was found between bile stasis and HFI. Estrogenic effects have been noted in relation to cholestasis (Kobayashi et al., 2013), which histologically manifests as bile stasis. A significant decrease in estradiol, hypothesized to relate to HFI, would then show no bile stasis, as observed in our research findings. There was one histological liver sample in which a metastasis of an endocrinological origin was observed. In this specific case, atrophic testes and decreased numbers of interstitial cells were observed as well as HFI category C. Since this study was small and only one such case was found, this particular finding does not hold much value. However, it may be beneficial to further investigate such correlations and the effect of such metastasis on estradiol production.

The results of this study strongly indicate a hormonal relationship to HFI. Overall, the findings indicate that a decrease from a baseline level of estradiol has an effect on HFI. Further studies may be performed using a larger population of cadavers to gain more accurate statistics and results, and further sampling of other endocrine tissues, such as the pituitary and pancreas. Although estradiol has been shown to maintain bone mass density (Grundberg et al., 2007), additional research may be useful for examining the relationship between estradiol and bone mass formation, specifically in relation to the flat bones of the skull (Niada et al 2016). In males there is a well-known relationship of estradiol to maintenance of bone during aging (Russell \& Grossman, 2019), though it isn't clear whether this manifests as a mobilization of calcium for deposition elsewhere in soft tissues as can be found in cases of cholecalciferol toxicity (Kocher et al., 2010). Furthermore, since estradiol is necessary for epiphyseal fusion (MacGillivray et al., 1998), studies should look into the effects of estradiol on the sutures of the skull, particularly the coronal suture. Though most research seems to indicate a relationship of estradiol to bone growth early in development (Flöter et al., 2016), studies of animal models and/or humans of advanced age may be better suited for understanding this etiology. If access is granted to medical records of cadavers, the physiologic manifestation of HFI causes and effects may be more accurately observed and recorded.
In addition, an important consideration is the possible relation of HFI to dementia, as this relationship can be defined with two distinct mechanisms. One such mechanism could involve the direct effect of the cranial bone thickening on the brain tissue itself. The severity of HFI has been correlated with the decrease in intracranial volume. There may be a possible association between HFI and the beginning of cognitive decline (May et al., 2012). Further studies can investigate the symptomatic effects of HFI on postmenopausal women, especially since it has been more prevalent nowadays compared to older generations (May et al.).

Another mechanism for HFI connection to dementia could be the estrogen exposure itself. Estrogenic receptors have been noted to be present in important regions of the brain for learning and memory, such as the prefrontal cortex and hippocampus (McEwen et al., 2012). In fact, estrogen also affects glucose metabolism in the brain. Towards menopause, the decrease in estrogen results in a decrease in glucose metabolism in the brain. The compensatory pathways have been observed to contribute to the deposition of amyloid beta proteins, a key mechanism is the development of Alzheimer's disease (Yao et al., 2012; Ding, et al., 2013; Yin et al., 2015; Rettberg et al, 2016). Further studies could examine whether HFI can indirectly affect brain function through the effects of estrogen exposure. Although studying HFI is limited by physicians today, understanding the effects of HFI on brain function could lead to a screening test for post-menopausal women in the future. HFI has been associated with decreased estrogen, which in turn has already been shown to be connected to dementia on many accounts. Therefore, it would stand to reason that HFI may indirectly serve as a good screening tool for possible development of dementia.

Such an investigation has the power to unlock the mysteries of HFI and potentially prevent patients from any suffering that may be caused from this unknown etiology. If such a large percentage of post-menopausal women have this, it is essentially "normal". Could this be a treatable pathology hiding in its prevalence?

\section{ACKNOWLEDGEMENTS}

O'Connor (NYITCOM) processed tissues and produced slides. NYITCOM Anatomy Department provided access to the cadavers used for its Gross Anatomy coursework, and we thank the donors for their generous contribution. 
BEATTY, B.; PUTCHA, K.; SHAH, A. \& LI, K. Asociaciones histopatológicas de órganos con hiperostosis frontal interna en humanos. Int. J. Morphol., 39(1):77-83, 2021.

RESUMEN: Un aumento del engrosamiento del hueso frontal, por adiciones laminares irregulares en la superficie interna, justo en la profundidad de la duramadre, se conoce en los registros arqueológicos y médicos como hiperostosis frontal interna (HFI). La distribución de ésta, se restringe idiosincráticamente al hueso frontal y no tiene etiología conocida. La prevalencia entre las mujeres posmenopáusicas y la rareza en los hombres sugiere que se debe a las hormonas. Aquí informamos los hallazgos histopatológicos de órganos hormonalmente activos (hipófisis, gónadas e hígado) de una muestra de cadáveres geriátricos en la que se evaluó HFI. La HFI estuvo presente en el $50 \%$ de los hombres (7/14) y el $95 \%(21 / 22)$ de las mujeres. Todos los hombres con HFI tenían atrofia testicular o no tenían testículos. En los hombres con HFI categoría C o D se observó atrofia testicular de moderada a grave. Hubo una disminución en el número de células intersticiales (células de Leydig) en el 83,3 \% de los hombres con HFI. En 21de 22 mujeres se observó evidencia de HFI, y las patologías ováricas se distribuyeron de manera desigual (fibromas en dos) y la mayoría exhibió signos de estar sana y posmenopáusica. Las patologías hepáticas tenían patrones opuestos entre los sexos, con más patologías hepáticas entre los hombres sin HFI (particularmente congestión pasiva y estasis biliar). Las excepciones fueron que el único caso de neoplasia hepática se encontró en un varón con HFI y se presentó esteatosis en dos casos con HFI y un caso sin HFI. En las mujeres, todos los casos de patologías hepáticas (esteatosis, hepatitis, congestión pasiva, fibrosis y estasis biliar) se asociaron con HFI. $\mathrm{Al}$ parecer la patología gonadal está más estrechamente asociada con la HFI en los hombres que en las mujeres, lo que sugiere un rol del estradiol en este crecimiento inusual de hueso en hombres de avanzada edad. Sería importante realizar investigaciones más detalladas precisas respecto a la hiperostosis frontal interna.

PALABRAS CLAVE: Hiperostosis frontal interna; Cráneo; Crecimiento óseo; Estradiol; Histología.

\section{REFERENCES}

Belcastro, M. G.; Facchini, F. \& Rastelli, E. Hyperostosis Frontalis Interna and sex identification of two skeletons from the Early Middle Ages necropolis of Vicenne-Campochiaro (Molise, Italy). Int. J. Osteoarchaeol., 16(6):506-16, 2006.

Devriendt, W.; Piercecchi-Marti, M. D.; Ardagna, Y.; Mahieu, E.; Hershkovitz, I.; Signoli, M. \& Dutour, O. Two neolithic cases of Hyperostosis frontalis interna. Int.J. Osteoarchaeol.,14(5):414-8, 2004.

Ding, F.; Yao, J.; Rettberg, J. R.; Chen, S. \& Brinton, R. D. Early decline in glucose transport and metabolism precedes shift to ketogenic system in female aging and Alzheimer's mouse brain: implication for bioenergetic intervention. PLoS One, 8(11):e79977, 2013.

Dunlop, D. J. \& Stirling, A. J. Thoracic spinal cord compression caused by hypophosphataemic rickets: a case report and review of the world literature. Eur. Spine J., 5(4):272-4, 1996.

Flöter, V. L.; Galateanu, G.; Fürst, R. W.; Seidlová-Wuttke, D.; Wuttke, W.; Möstl, E.; Hildebrandt, T. B. \& Ulbrich, S. E. Sex-specific effects of low-dose gestational estradiol-17b exposure on bone development in porcine offspring. Toxicology, 366-367:60-7, 2016.
Hall, B. K. Bones and Cartilage: Developmental and Evolutionary Skeletal Biology. Amsterdam, Elsevier Academic Press, 2005.

Hershkovitz, I.; Greenwald, C.; Rothschild, B. M.; Latimer, B.; Dutour, O.; Jellema, L. M. \& Wish-Baratz, S. Hyperostosis frontalis interna: An anthropological perspective. Am. J. Phys. Anthropol., 109(3):303-25, 1999.

Jeffery, N. Differential regional brain growth and rotation of the prenatal human tentorium cerebelli. J. Anat., 200(2):135-44, 2002.

Kocher, D. K.; Kaur, G.; Banga, H. S. \& Brar, R. S. Histopathological changes in vital organs of house rats given lethal dose of cholecalciferol (vitamin D3). Indian J. Anim. Res., 2(3):193-6, 2010.

Mann, R. W. \& Hunt, D. R. Photographic Regional Atlas of Bone Disease. Springfield, Charles C. Thomas, 2005.

May, H.; Mali, Y.; Dar, G.; Abbas, J.; Hershkovitz, I. \& Peled, N. Intracranial volume, cranial thickness, and hyperostosis frontalis interna in the elderly. Am. J. Hum. Biol., 24(6):812-9, 2012.

McEwen, B. S.; Akama, K. T.; Spencer-Segal, J. L.; Milner, T. A. \& Waters, E. M. Estrogen effects on the brain: actions beyond the hypothalamus via novel mechanisms. Behav. Neurosci., 126(1):4-16, 2012.

Mulhern, D. M.; Wilczak, C. A. \& Dudar, J. C. Brief communication: unusual finding at Pueblo Bonito: multiple cases of hyperostosis frontalis interna. Am. J. Phys. Anthropol., 130(4):480-4, 2006.

Opperman, L. A.; Sweeney, T. M.; Redmon, J.; Persing, J. A. \& Ogle, R. C. Tissue interactions with underlying dura mater inhibit osseous obliteration of developing cranial sutures. Dev. Dyn., 198(4):312-22, 1993.

Presley, R. Preconception of Adult Structural Pattern in the Analysis of the developing Skull. In: Hanken, J. \& Hall, B. K. (Eds.). The Skull Volume 1. Development. Chicago, The University of Chicago Press, 1993. pp.34777.

Rettberg, J. R.; Dang, H.; Hodis, H. N.; Henderson, V. W.; St John, J. A.; Mack, W. J. \& Diaz Brinton, R. Identifying postmenopausal women at risk for cognitive decline within a healthy cohort using a panel of clinical metabolic indicators: potential for detecting an at-Alzheimer's risk metabolic phenotype. Neurobiol. Aging, 40:155-63, 2016.

Rühli, F. J.; Kuhn, G.; Evison, R.; Müller, R. \& Schultz, M. Diagnostic value of micro-CT in comparison with histology in the qualitative assessment of historical human skull bone pathologies. Am. J. Phys. Anthropol., 133(4):1099-111, 2007.

Stewart, W. F.; Lipton, R. B.; Celentano, D. D. \& Reed, M. L. Prevalence of migraine headache in the United States. Relation to age, income, race, and other sociodemographic factors. JAMA, 267(1):64-9, 1992.

Yao, J.; Irwin, R.; Chen, S.; Hamilton, R.; Cadenas, E. \& Diaz Brinton, R. Ovarian hormone loss induces bioenergetic deficits and mitochondrial bamyloid. Neurobiol. Aging, 33(8):1507-21, 2012.

Yin, F.; Yao, J.; Sancheti, H.; Melcangi, R. C.; Morgan, T. E.; Finch, C. E.; Pike, C. J.; Mack, W. J.; Cadenas, E.; et al. The perimenopausal aging transition in the female rat brain: decline in bioenergetic systems and synaptic plasticity. Neurobiol. Aging, 36(7):2282-95, 2015.

\author{
Corresponding author: \\ Brian L. Beatty \\ New York Institute of Technology \\ College of Osteopathic Medicine \\ Department of Anatomy \\ Old Westbury \\ New York 11568 \\ USA
}

Email: bbeatty@nyit.edu 